\title{
Establishment of the Real Estate Bubble Warning Indicator System and
}

\section{Early Warning}

\author{
Zhongfu Qin ${ }^{1, a}$, Liqing Meng ${ }^{2, b}$, Shulian $\mathrm{Wu}^{3, \mathrm{c}}$ \\ ${ }^{1,2}$ College of Civil Engineering and Architecture Zhejiang University, Hangzhou, China \\ ${ }^{3}$ College of Civil Engineering and Architecture Zhejiang Sci-tec University, Hangzhou, China

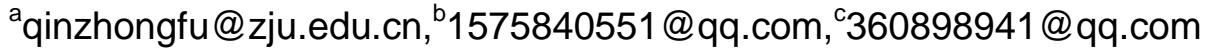

Keywords: Real Estate Bubble; Early Warning; Thelndicator System.

\begin{abstract}
In recent years, the demands for buying a house are suppressed by the rising and high housing price in the property market. The industry and educational circles have the question that whether the housing price is reasonable or not. Researchers should urgently investigate the existence of the property market bubble? If there is, researchers should know whether the bubble will be an economic threat. Perfect bubble warning mechanism could prevent the huge real estate bubble and a tremendous impact on our economic security. Based on this, this paper arranges, analyzes and summarizes the evaluation of the real estate bubble index; then studies the property market in Ningbo City, makes the measurement and analysis of single indicator, and builds a comprehensive system of early warning indicators by principal component analysis. At last, the paper gets the development status of property market according to the comprehensive early warning indicator.
\end{abstract}

\section{Introduction}

"House Ownership" has always been a top priority in our society for every family, and the demands of buying a house are suppressed by the rising and high housing price in the property market. The industry and educational circles have the question that whether the housing price is reasonable or not. Researchers should urgently investigate the existence of the property market bubble. [1 4]

Kindleberger gave the most famous foreign definition of bubble [5]. Zhenliang Cao (2006) gave a more comprehensive domestic definition of bubble [6]. In short, bubble is a phenomenon that the price is a serious deviation from the value. Real estate is similar to stocks, bonds, antiques as bubble carriers [7].

There are many ways to measure the extent of the real estate bubble. For example, the indicators measure the bubble; the comparison between the market price and theoretical price to measure the bubble directly[1]; by statistical discovery rules to measure foam; from the "market imbalance" Soros hypothesis starting to measure[8]. In various professional investigations or government reports, the method for evaluating the real estate bubble is the indicator system $[2,9,10]$. The indicator system is divided into "single indicator method" and "comprehensive indicator method"[2]. The indicator method has its unique characteristics and advantages. For example, the operation is not difficult; the calculation is simple; it's easy to understand and so on. Therefore, the study used the real estate bubble indicator system for early warning. 
In the selection of indicators and methods is different, the wise see wisdom. For example, Hang Li (2010) selected the supply, and demanded that two types of evaluation indicators were analyzed, in order to determine whether the bubble generated [11]. Li Liu (2010) built a more comprehensive bubble evaluation model on the basis of a combination of five indicators to determine the development of the relevant circumstance [10].Liying Feng and Haixia Li (2012) selected six indicators for research and combined with factor analysis [12]. Wen Yin (2013) combined with principal component analysis after the selection of indicators to empirical research on a number of cities [13].

Therefore, this paper reads indicators that measure the real estate bubble for reference, and discusses the extent of the real estate bubble and timely warning, which have important significance on the theory and practice.

\section{Early Warning in the Property Market}

Different types of indicators can reflect different degrees of development and dimensions of the real estate bubble. Here need to select scientific, comprehensive and reasonable early warning indicators to measure the development of the real estate bubble.

Early warning indicators' selection principle is as follows: one is the principle of representation: the selected indicators can be a good representative of the degree of the real estate bubble development. Second, the comprehensive principle: the selected indicators can reflect the various factors affecting the real estate bubble and could highlight the main factors. Third, the principle of comparability: the selected indicators of the best horizontal or vertical comparison. Fourth, principles to be measurable: the selected indicators can be reflected in numerical form to facilitate data analysis. Fifth, the principle of multi-type: the selected indicators can reflect different states of development of bubble, such as speed, size, degree, etc.

In many real estate single indicators, taking into account the selection principle of early warning indicators and referring to many relevant articles [14 16]. This paper selected the following eight early warning indicators, which have representative (Table 1).

The single early warning indicator. In the single indicator measure, the study lists eight indicators that have warning properties and divide the critical value of slight bubble and serious bubble. The critical value refers to a lot of similar comprehensive articles [3, 13, 15 and 16]. Then, calculate the specific indicators based on specific data of the property market in Ningbo: the overall average value (a) and the average of the last three years (b). By the indicator value compares with the critical value, researchers can easily determine whether there is a bubble and the severity of the bubble. Then, researchers can make bubble warning. You can very clearly see total degree of bubble over the years (by a), as well as the future development trend of bubble (by b) in Table 1.(Note: all of the data is from the statistical yearbook of Ningbo City.

Table 1 Set the Critical Value Method to Warn the Real Estate Bubble

\begin{tabular}{|l|c|c|c|c|}
\hline \multicolumn{1}{|c|}{ Specific Indicators } & \multicolumn{2}{c|}{ Reference Standard } & \multicolumn{2}{c|}{ Actual Situation } \\
\cline { 2 - 5 } & Slight & Serious & a & b \\
\hline $\begin{array}{l}\text { X1: Investment in real estate development/the total } \\
\text { social investment in fixed assets }\end{array}$ & $0.25 \sim 0.30$ & $>0.30$ & 0.24 & 0.32 \\
\cline { 4 - 5 } $\begin{array}{l}\text { X2: The real estate investment growth rate / GDP } \\
\text { growth rate }\end{array}$ & $2 \sim 4$ & $>4$ & 1.72 & 2.43 \\
\hline X3: Housing construction area /completion of the area & $3 \sim 5$ & $>5$ & 4.02 & 4.85 \\
\cline { 4 - 5 } & & & Slight & Slight \\
\hline
\end{tabular}




\begin{tabular}{|c|c|c|c|c|}
\hline \multirow{2}{*}{$\mathrm{X} 4$ : The house price to income ratio } & \multirow{2}{*}{$8 \sim 10$} & \multirow{2}{*}{$>10$} & 8.35 & 8.86 \\
\hline & & & Slight & Slight \\
\hline \multirow{2}{*}{ X5: The total amount of the real estate sales / GDP } & \multirow{2}{*}{$0.13 \sim 0.16$} & \multirow{2}{*}{$>0.16$} & 0.11 & 0.10 \\
\hline & & & No bubble & No bubble \\
\hline \multirow{2}{*}{$\begin{array}{l}\text { X6: Residential rental price index / commodity retail } \\
\text { price index }\end{array}$} & \multirow{2}{*}{$1.00 \sim 1.10$} & \multirow{2}{*}{$>1.10$} & 1.02 & 1.01 \\
\hline & & & Slight & Slight \\
\hline \multirow{2}{*}{$\begin{array}{l}\text { X7: The real estate development loans / capital source } \\
\text { of real estate development enterprise; }\end{array}$} & \multirow{2}{*}{$0.25 \sim 0.35$} & \multirow{2}{*}{$>0.35$} & 0.23 & 0.24 \\
\hline & & & No bubble & No bubble \\
\hline \multirow{2}{*}{$\begin{array}{l}\text { X8: The real estate sales growth rate/ the real estate } \\
\text { sales area growth rate }\end{array}$} & \multirow{2}{*}{$1.5 \sim 2.0$} & \multirow{2}{*}{$>2.0$} & 2.13 & 1.05 \\
\hline & & & Serious & No bubble \\
\hline
\end{tabular}

In the past three years, among eight individual indicators (based on the value of $b$ ), there are four indicators that pointed to a slight bubble, and the other 3 indicators fell in the safe range. An indicator leven expressed serious real estate bubble. The probability of the normal operation of the property market is $62.5 \%$. From a historical point of view, three indicators showed slight foam. One indicator is a serious bubble. From an overall point of view, the probability of the normal operation of the property market in Ningbo city is $50 \%$. Therefore, Ningbo property market is generally stable, but there are trends. Although it's not very serious, but need to guard against.

Among them, the individual indicators fund serious bubble, which need to focus on. For example, this early warning indicator "investment in real estate development/the total social investment in fixed assets" warned the emergence of the bubble, then researchers need to be vigilant about whether the real estate industry increases the proportion of investment in society, while reducing the investments in other economic entities, which affects the balance of investment in fixed assets structure and thus poses a threat to regional economic security. "The real estate sales growth rate/ the growth rate in real estate sales areas" indicator displayed as a serious bubble in the average over the years. From the data structure, because the indicator value in 2004 was 16.14, much higher than other years. This is because the average price of commercial housing of Ningbo rose $26.47 \%$ in September 2004,, as compared with the beginning of the year, even higher than the past three year's average increase of $19.6 \%$. Housing price shows an accelerated upward trend.

Comprehensive Early Warning Indicator. There is a large correlation between individual warning indicators. Although this paper carefully brushes the eight individual indicators chosen for the development of the regional real estate bubble warning, the correlation between the indicators of this problem is inevitable. Then here presents a model design of comprehensive early warning indicator to solve this problem.

In practice studies, to avoid missing important information to consider as much as possible indicators, the increase indicators will increase the load $f$ the study, some of the information's overlapping is inevitable. Therefore, the researchers expect to brush the selected information through linear transformation as much as possible. Principal component analysis (PCA) emerges as the time requires. PCA combines with a group of independent variables through the linear transformation of the original variable, in order to reflect the information of original variables as much as possible.

In this paper, the PCA was carried out with SPSS19.0 software. From the characteristic value and the variance contribution rate, the variance contribution rate of the first three ingredients dominate, the cumulative variance contribution rate is $78.370 \%$. Therefore, the former three ingredients have been able to explain $78.370 \%$ of the variance, indicating that the eight original variables can be composed of three common factors to represent the primary information of the original variables. 
This paper uses SPSS to obtain the characteristic value and the variance contribution rate, the rotating factor loading matrix, eigenvector matrix(omitted here), and gets PCA expressions (ZXi is standardization of data):

$$
\mathrm{F}_{1}=0.411683 \mathrm{ZX}+0.271866 \mathrm{ZX}_{2}+0.523417 \mathrm{ZX}_{3}+0.437376 \mathrm{ZX}_{4}+0.330422 \mathrm{X}_{5}-0.273061 \mathrm{ZX}+0.28
$$

$3816 \mathrm{ZX}_{7}-0.163717 \mathrm{ZX} 8$

$\mathrm{F}_{2}=0.226455 Z X_{1}+0.476214 Z X_{2}+0.074091 Z_{3}-0.367467 Z_{4}-0.241991 Z X_{5}+0.422438 Z X_{6}+0.4$ $17658 \mathrm{ZX}_{7}+0.146987 \mathrm{ZX} 8$

$$
\mathrm{F}_{3}=0.216895 Z X_{1}-0.113526 Z X_{2}+0.195982 Z_{3}-0.066323 Z_{4}-0.198970 Z X_{5}-0.183435 Z X_{6}-0.162
$$

\section{$522 \mathrm{ZX}_{7}+0.429608 \mathrm{ZX}_{8}$}

According to the basic principles and steps of principal component analysis, the principal component contribution rate is set to the weight value, weighted sum, synthesis of comprehensive early warning indicator $\mathrm{F}$, the values are shown in Table 2:

$$
\mathrm{F}=35.015 \% \mathrm{~F}_{1}+29.812 \% \mathrm{~F}_{2}+13.544 \% \mathrm{~F}_{3}
$$

Table 2 Comprehensive Early Warning Indicator

\begin{tabular}{ccccccccccccc}
\hline Year & $\mathbf{2 0 0 2}$ & $\mathbf{2 0 0 3}$ & $\mathbf{2 0 0 4}$ & $\mathbf{2 0 0 5}$ & $\mathbf{2 0 0 6}$ & $\mathbf{2 0 0 7}$ & $\mathbf{2 0 0 8}$ & $\mathbf{2 0 0 9}$ & $\mathbf{2 0 1 0}$ & $\mathbf{2 0 1 1}$ & $\mathbf{2 0 1 2}$ & $\mathbf{2 0 1 3}$ \\
\hline F & 0.038 & 0.100 & -0.026 & -1.033 & -0.726 & -0.580 & -1.048 & -0.007 & 0.937 & 0.535 & 0.893 & 0.917
\end{tabular}

From the linear trend line of the comprehensive early warning indicator of real estate bubble, researchers can see (Fig. 1) that Ningbo real estate market bubble shows a linear upward trend in recent years, indicating real estate market in general continued to boom, the real estate bubble appears gradually. There is a tendency to expand. The bubble comprehensive indicator value is positive in 2002 to 2004, but its value is small. Then, from 2004 to 2009, the comprehensive indicator is negative, indicating that there is no real estate bubble. However, from 2010 to 2013, the indicator value is positive. In 2010, 2012, 2013, the indicator value is significantly larger, reflecting the real estate bubble has a tendency to grow. Researchers should be vigilant.

Table 3 The Design of the Early Warning Table

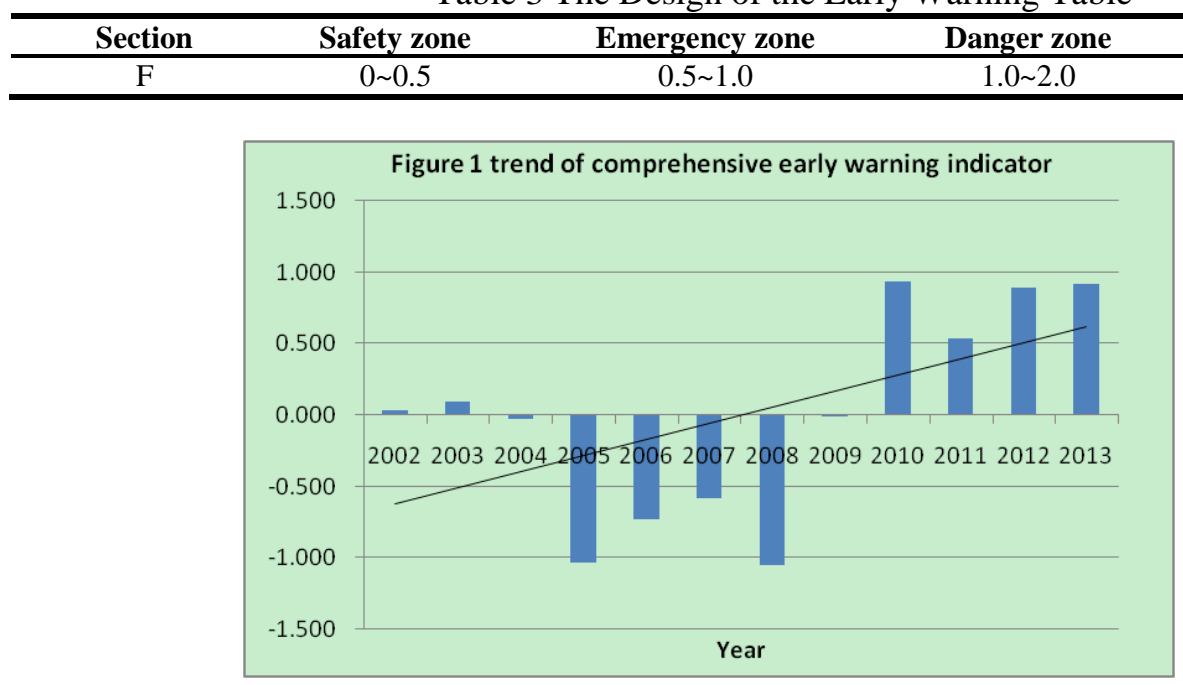

In this paper, the design of the real estate bubble early warning table (Table 3). Researchers can see the value is in the emergency zone from 2010 to 2013. Therefore, the development of Ningbo real estate market is stable generally, but a slight bubble. The appropriate bubble is conducive to the development of competition in market, be not too panic. But to plan ahead and be prepared at any time is not over, researchers have to maintain this steady development trend and prevent overheating real estate market in general and lead to a bubble economy, even develop into an economic crisis. 


\section{Summary}

Based on the specific early warning indicators, this paper constructs an early warning index system of the real estate market bubble. This early warning indicator system can be applied to other areas of the real estate market. Researchers carried out timely and effective early warning of the real estate market bubble is conducive to the stable development of the regional real estate market.

This paper draws a conclusion that generally the market is stable in Ningbo, and there is a little bubble, but the warning indicator range segment division is somehow subjective, which is lack of empirical theory on economics. Researchers hope that the future can verify.

\section{References}

[1] Yifei Lai, Ya Zhou, Yuanxin Wei, Study on the Real Estate Bubble based on the Fundamental Value -- a Case of Shenzhen,J.Journal of Wuhan University (Philosophy and Social Science Edition), 4(2012)98-102.

[2] Xiaoyu Hu. The Real Estate Bubble Degree of Chongqing City -- Based on the Indicators, J. Market Modernization, 7(2012)103 104.

[3] Jinmei Wang, Bin Chen,Ying Li, The Economic Model Design of the Real Estate Industry's Price Bubble-- based on the Improved CAPM Model, J. Chinese Price,12(2008)39 40.

[4] Zeyu Wang, Study and Evaluate the Real estate Bubble based on BP Neural Network, J.Theory and Practice of Finance and Economics, 4(2013)95-98.

[5] Peter Newman: "New Palgrave Dictionary of Economics", Science Press.2005.

[6] Zhenliang Cao, Bubble Theoretical Framework and the Chinese Real Estate Related Empirical, J. Journal of Guizhou University of Finance and Economics,5(2006).

[7]Lina Wang, The Formation Mechanism and Prevention Measures of the Real Estate Bubble, J. Finance science,1(2003)92 97.

[8] Kailan Wu,The Real Estate Bubble Empirical Research of Chengdu City, D. Sichuan Normal University, 2010.

[9] Zicheng Wang, Juan Ming, An Empirical Study of the Real Estate Bubble of the Pearl River -- a Case Study of Guangzhou, J. Economic Geography, 5(2007)819-822+846.

[10] Li Liu, Selection and Integration of the Real Estate Speculation Bubble Index, J. Commercial Era, 23(2010)133-134.

[11]Hang Li, An Empirical Analysis of the Real Estate Bubble in the Pan Yangtze River Delta, J. City Development, 7(2010)21 22.

[12] Liying Ping, Haixia Li. The Measurement and Analysis of the Real Estate Bubble based on Factor Analysis, J.Chinese Real Estate: Academic Edition, 12(2012)19 30.

[13] Wen Yin,Study of the Real Estate Bubble in China's Large and Medium-sized City, J. Economic Forum, 6(2013)90-95.

[14]Lin Liu, Ying Huang, Hongyu Liu, Study on the Real Estate Bubble Coefficient, J. Price Theory and Practice, 3(2003). 
[15] Jin Li, Xionglang He, An Empirical Study of the Real Estate Bubble in China, J. Journal of South-central University for Nationalities: Social Science Edition, 30 (2010 123 126.

[16] Yinglai Shi, Ping Wang, Study on the Real Estate Early-warning Indicator System and Comprehensive Early Warning Method, J. Statistical Research, 28(2011) 18. 